

\section{GENALGUACIL, EL MUSEO HABITADO}

\section{GENALGUACIL, THE INHABITED MUSEUM}

\section{Licenciada en Historia del Arte por la Universidad de Málaga y Máster en Arte Contemporáneo por la Universidad de Londres}

\section{Malgara García Díaz Historiadora y arqueóloga por la Universidad de Málaga}

Resumen Este artículo recoge la extraordinaria experiencia que se vive en un pequeño pueblo de la provincia de Málaga, un magnífico ejemplo de cómo el arte y la cultura pueden ser motor de desarrollo rural. En 1994, a iniciativa municipal, se puso en marcha un programa de creación y exposición de arte contemporáneo en el que, además, se implicó la casi totalidad del vecindario. Encuentros de Arte, Arte Vivo, el Museo, el proyecto Lumen y todas las actividades que se han generado en torno a ellos, constituyen la columna vertebral sobre la que se sostiene una propuesta seria y bien diseñada que se sustenta en elementos tradicionales del pueblo, al tiempo que en las más recientes y vanguardistas propuestas artísticas. Los y las artistas, que han ido participando en las diferentes convocatorias y ediciones, han ido conformando una extraordinaria colección de piezas y experiencias estéticas que contribuyen a afianzar la personalidad de la población y a sacarla de la crisis que afecta a muchas poblaciones del interior, que ven mermar su número de habitantes. Genalguacil se aferra a estas propuestas culturales bajo el paraguas de «Genalguacil Pueblo Museo» para mejorar su economía a través del turismo cultural y hacerse un hueco en las dinámicas artísticas y culturales del país. El resultado es un museo habitado que ha logrado focalizar muchas miradas y que tiene ahora entre sus manos un futuro prometedor.

Palabras clave Arte contemporáneo, arte urbano, gestión, participación.

Abstract This article describes the extraordinary experience offered by a small town in the province of Málaga, a fabulous example of how art and culture can be an engine of rural development. In 1994, a program of creation and exhibition of contemporary art was launched by the town council in which almost the entire neighbourhood got involved. Art Meetings, Live Art, the Museum, the Lumen project, as well as all the activities generated around them, constitute the backbone which supports a serious and welldesigned proposal inspired by the town's traditional elements as well as by the newest artistic proposals. The artists, who have participated in every edition, have gathered an extraordinary collection of pieces and aesthetic experiences that consolidate the personality of the local population and are helping many inland villages overcome the crisis as they are being deserted by many of their residents. Genalguacil is clinging to these cultural proposals under the umbrella of «Genalguacil Pueblo Museo» in order to improve its economy through cultural tourism and find its place in the country's artistic and cultural dynamics. The result is an inhabited museum that has managed to get a lot of attention and has now a promising future ahead.

Keywords Contemporary Art, Urban Art, Cultural Management, Collaboration. 


\section{Genalguacil}

Recostado en una ladera de las estribaciones más occidentales de la cordillera Penibética, tramo conocido como la Serranía de Ronda, se localiza la población, que comparte con sus vecinas un atractivo tipismo: pequeños enclaves de vibrante blanco, recorridos por estrechas y sinuosas calles que originan reducidos espacios, en los que la vida se sucede tanto intra como extramuros y donde la huella morisca es aún palpable. Las labores agrícolas a las que, de forma mayoritaria se dedican sus gentes, el trasiego cotidiano y el aislamiento de los grandes núcleos de la, no obstante próxima costa, les confieren un cierto aire de postal antigua que se vuelve sepia, ya que el despoblamiento al que se ven sujetos es tan constante como inmarcesible la belleza que se comprueba en cada uno de sus rincones.

Rodeado de espesos bosques de castaños, pinos, alcornoques y una joya relicta, los pinsapos; enclavado en las montañas, donde las alturas lo envuelven en transparentes atmósferas azules; y surcado por los arroyos que acompañan al río Genal y que circulan, ondulantes, en la profundidad de fragantes y profundos valles. Este es el enclave de Genalguacil, un reluciente caserío en medio del bosque, ya que la única manera de acceder a él es cruzar la espesura: el «Jardín del Visir», si nos ceñimos al descriptivo topónimo de origen andalusí, al que contribuyen sus temperaturas suaves y sus relativamente abundantes precipitaciones.

Sin embargo, sus poco más de 400 vecinos envejecen y los jóvenes se van a la cercana Costa del Sol a buscar oportunidades en el turismo masivo, y el abandono amenaza con sumirlo en una profunda crisis de difícil salida. Este ha sido el motivo por el cual, desde el propio Ayuntamiento de Genalguacil, se inició una dinámica que tenía como núcleo central al arte contemporáneo, y la participación del vecindario en el proceso de creación como finalidad.

\section{El proyecto}

Con la mente puesta en promover actuaciones que hicieran desarrollar la localidad y frenaran el retroceso poblacional, en 1994 vio la luz la primera edición de lo que entonces se llamó Talleres Artísticos del Valle del Genal. Ya, desde sus inicios, se adoptó el sistema que aún se mantiene a día de hoy en los Encuentros de Arte: el ayuntamiento lanza una convocatoria, un número indeterminado de artistas presentan sus proyectos, un jurado selecciona los más apropiados y durante la primera quincena de agosto se celebran las actividades y se procede a la generación de las obras.

Los artistas se desplazan hasta Genalguacil, allí se les proporciona alojamiento y manutención gratis, así como algunos materiales, por lo general de origen local, para la realización de sus trabajos. Durante esas dos semanas conviven con los habitantes que, como hemos dicho, en muchas ocasiones incluso participan en la transformación de los materiales y en la producción artística. Finalmente, las bases del concurso indican que la obra debe quedar instalada en Genalguacil y cada artista, en la actualidad, recibe también la cantidad de 1000 euros.

Las propuestas seleccionadas para este año 2020 se han visto reducidas a siete, ya que la crisis sanitaria desaconseja las multitudes. Christos Papasotiriou recoge sonidos del pueblo para después intervenir sobre ellos, Raquel Serrano se enfrenta al reto de realizar dibujos sobre fachadas con la técnica de frottage, Jesús Palomino investiga y descubre los diferentes blancos del pueblo, Eduardo Rodríguez y José Manuel Ruiz realizan tejas de jabón, Ana Varea interviene en "La casa de Fulanita», Rafael Jiménez trabaja sobre azulejos con plastilina, empleando nuevas tecnologías para su elaboración, y Paula Valdeón, con su iniciativa «Un paisaje verde», crea una pieza pictórica que mezcla tejido, pintura, dibujo y cerámica.

Durante quince días, además de los trabajos propios de los y las artistas, se suceden diferentes 


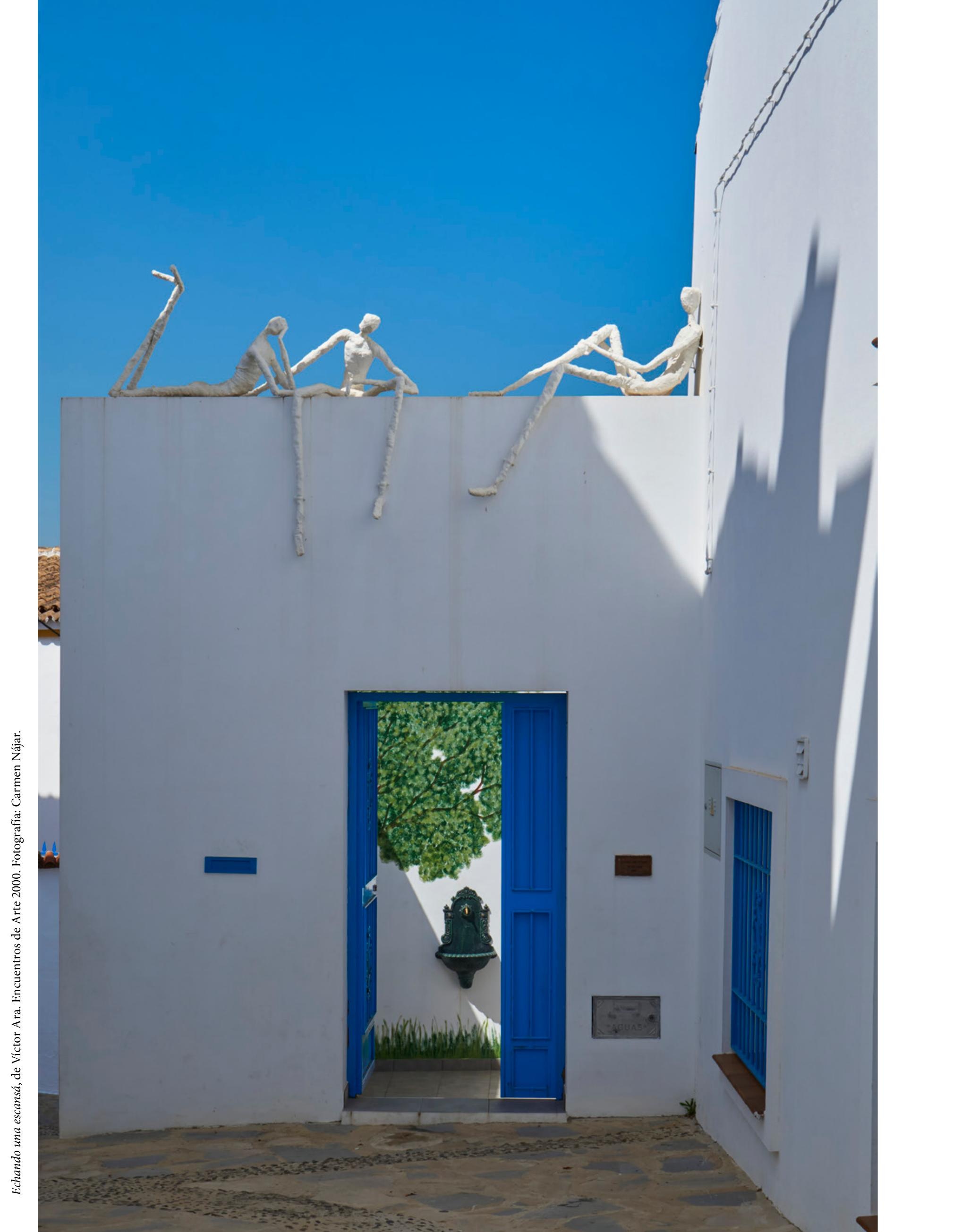




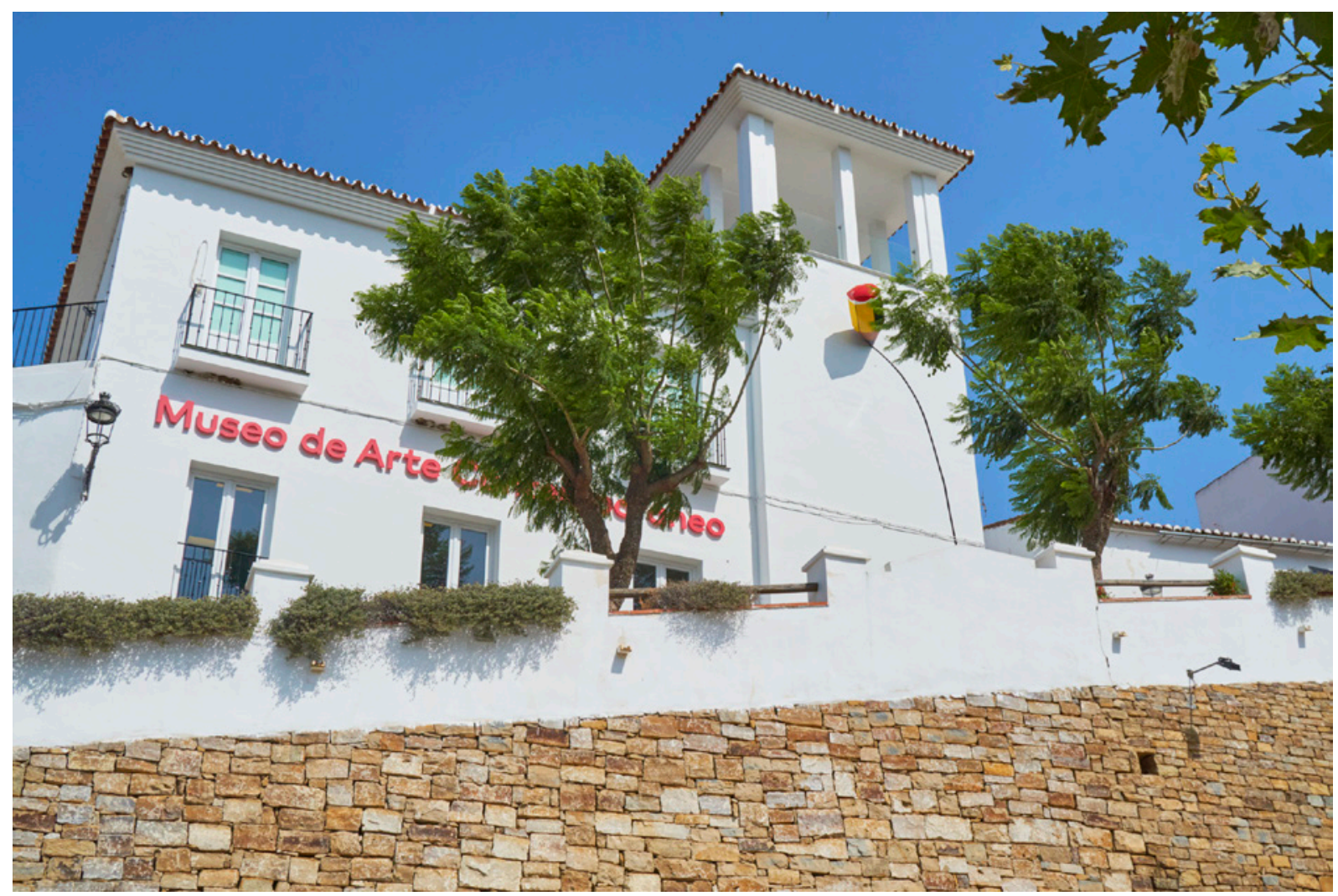

Fachada del MAC con la obra El lápiz, una intervención de Javier Calleja en Arte Vivo 2015. Fotografía: Carmen Nájar.

talleres por las mañanas, en los que predomina un cierto carácter instructivo y formativo, que se convierten en una amplia oferta cultural cuando llega la tarde, especialmente, con el programa de las Noches al Fresco. Conciertos, teatro, espectáculos de luces, danza, pasacalles, circo, etc., proporcionan más oportunidades para la concurrencia y para el disfrute de la cultura y el encuentro.

Este modelo de funcionamiento, por buscarle paralelos, es muy parecido al que se puso en marcha en Hecho (Huesca) y existe otro antecedente, igualmente en los años ochenta, en la localidad italiana de Ulassai. A ambos lugares se trasladan los artistas, montan su taller, ejecutan su obra y esta pasa a formar parte del patrimonio artístico de los pueblos. Algo anterior a estos proyectos, en la bella localidad marroquí de Asilah, se puso en marcha también una experiencia similar, el Festival de las Artes, escenario en el que artistas locales y foráneos crean para «la involucración en el conocimiento, transformación y preservación de su entorno vital» (Gómez López, 2015).

Volviendo a Genalguacil, las tres primeras celebraciones fueron consecutivas, los años 94, 95 y 96, pasando posteriormente a convertirse en Encuentros de Arte, con carácter bianual, motivo por el cual, en este 2020, se cumplen quince ediciones. Sin embargo, el pueblo no quería renunciar a sus citas con el arte en los veranos, con lo que los años acabados en número impar se programaban actividades lúdicas y formativas para la población, en la línea de las semanas culturales que se celebran en otros lugares. En 2011, estos esfuerzos se canalizaron a través de otra oferta más reglada a la que denominaron Arte Vivo.

Arte Vivo se define más como una propuesta de actividades culturales vinculadas con la artesanía, con la salvaguarda de valores, conocimientos y tradiciones. No obstante, en las últimas ediciones también se han integrado algunos artistas que han intervenido en el 


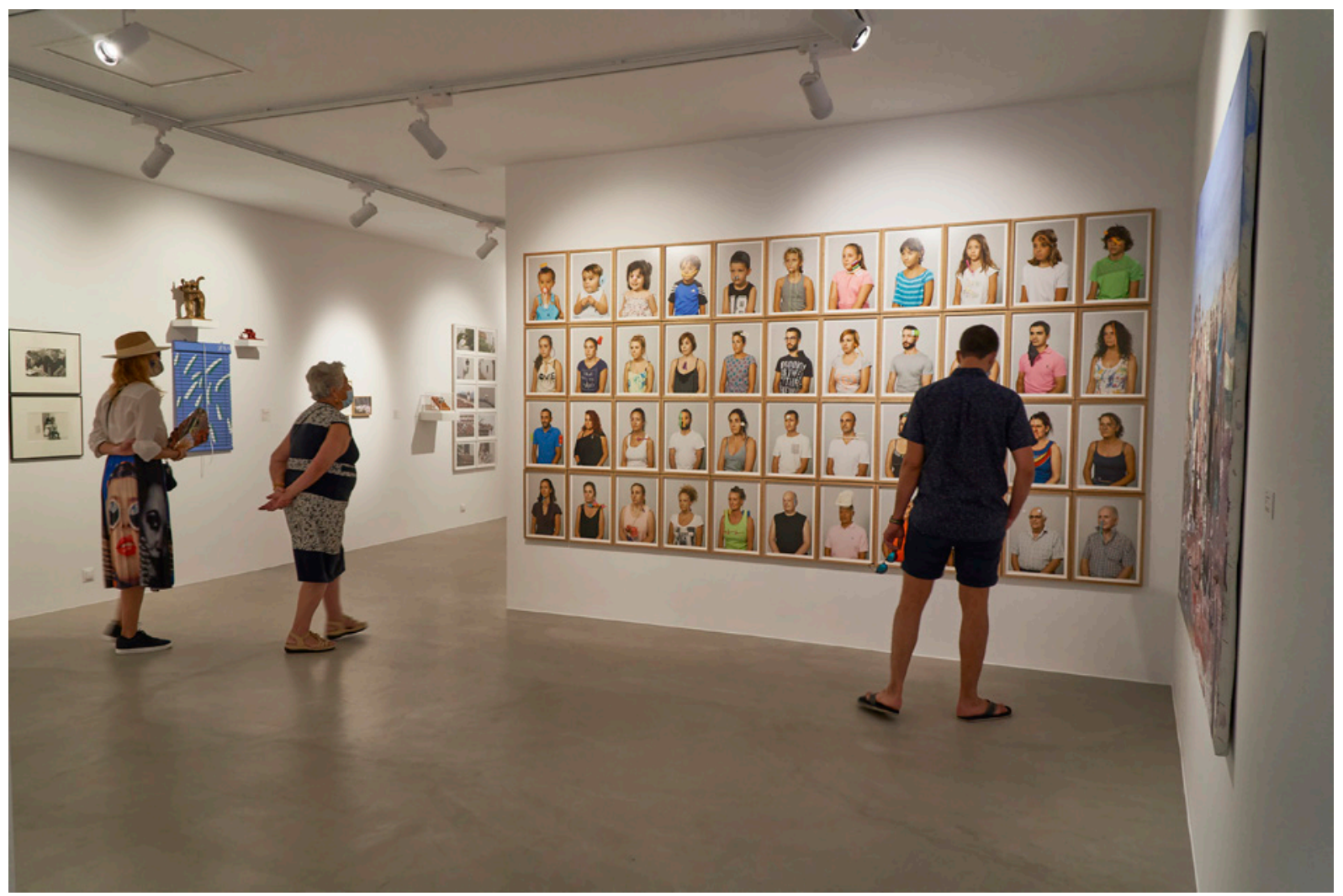

Exposición en el MAC: «25 años de historia». En primer plano, la obra Auto-Retrato de Arturo Comas, realizada en Arte Vivo 2015. Fotografía: Carmen Nájar.

pueblo, en el que han quedado emplazadas sus obras. Suelen ser artistas convocados expresamente y que subscriben el desarrollo de sus proyectos dentro de un esquema organizativo y expresivo en que ya se cuenta con un comisariado, que define el discurso expositivo y otorga coherencia al conjunto. En 2017 el proyecto se tituló «Pintar imaginarios» y en 2019 «Forjando identidades. Construyendo escenarios».

Paralelamente, y desde 2004, se cuenta con la presencia de un espacio expositivo cerrado, germen de lo que a día de hoy es una extraordinaria edificación, tanto física como conceptual, el Museo Fernando Centeno López, que lleva camino de convertirse en el buque insignia de la empresa para la que todo este ingente programa se puso en marcha.

La existencia del Museo facilita el poder albergar aquellas obras que su fragilidad aconseja conservar en un espacio protegido.
Pero, además, se trabaja ya intensamente en la celebración de exposiciones itinerantes y temporales, de manera que se focalicen buena parte de los esfuerzos y contactos que se han logrado, contando con la presencia de figuras que juegan un papel importante en el arte contemporáneo español. Por otro lado, también se persigue rentabilizar sus nada despreciables fondos, organizando hasta unas seis exhibiciones al año. Todo ello ha llevado a acometer unas profundas reformas que incluyen aspectos como la accesibilidad y la eficiencia energética, y que han visto la luz unos días antes de iniciarse los Encuentros de 2020 con la exposición «25 años de historia».

Cerca de 21000 personas han pasado el último año por él, lo que nos puede dar una idea de la acogida que está teniendo. Perfectamente equipado, ocupando el edificio de un antiguo molino de aceite, el Museo cuenta con diferentes salas provistas con las más recientes 
tecnologías relacionadas con la optimación de la luz y los espacios, y adaptadas a obras en cualquier tipo de soporte y formato, incluido el arte audiovisual.

Junto a los Encuentros, Arte Vivo y el Museo, se han incorporado otras temáticas como es el proyecto "Lumen», vinculado con el empleo de la luz en el arte contemporáneo, lo que se conoce como el light-art. Hablamos de la «combinación de materia, energía y nuevas tecnologías, así como de la interacción entre la luz y el color» (Pérez Castillo, 2019).

Las nuevas tecnologías permiten que la luz cobre materia y deje de ser un simple juego con su antagónica, la sombra, para convertirse en un recurso principal de expresión cargado de simbología. En palabras de los propios integrantes de la galería, que se ha desplazado a Genalguacil para desarrollar el proyecto: «Lumen es, efectivamente, un proyecto de arte público diseñado por la galería T20 Proyectos, que nace del diálogo con la gente y el pueblo, buscando generar fórmulas no transitadas en las que la luz sea el elemento central» (Pérez Castillo, 2019).

Además, con la incorporación de esta galería, se aúnan los proyectos de varios artistas que basan sus intervenciones en la localidad con instalaciones en las que la luz es la protagonista. La orografía de Genalguacil, rastros de luces para la memoria, la historia reciente o las señas de identidad son los temas en los que basan sus creaciones.

Comprobamos, por tanto, que se trata de un programa ambicioso y perfectamente formulado $y$ definido, $y$ que ha visto cómo se ramifican y hasta se legitiman sus propuestas primigenias. Por ejemplo, desde hace ya unos cuantos años, la organización es considerablemente cautelosa en el cumplimiento de la paridad, y se extrema el cuidado a la hora de elegir a los y las creadoras, de forma que las mujeres tengan igual presencia que los hombres. En Genalguacil, ellas sí están rompiendo el techo de cristal.
El iniciador de todo este movimiento, que fue alcalde de Genalguacil desde 1983 hasta 2003, Fernando Centeno López -el Museo lleva su nombre en reconocimiento a sus desveloslo explica con claridad: «los genalguacileños pasaron de espectadores a protagonistas, y algunos, los menos, de críticos a arduos defensores» (Algarra y Centeno, 2014). Y es que no podemos olvidar que, en el fondo, todo este proyecto trata de un profundo ejercicio de democratización del arte y de socialización de la cultura.

A Fernando Centeno le siguió Beatriz Álvarez Urda al frente del consistorio desde 2003 a 2011, y podemos asegurar que el trabajo no solo fue consolidándose, sino que siempre continuó creciendo y diversificándose. Y con la llegada a la alcaldía de Miguel Ángel Herrera Gutiérrez, en la práctica, se da comienzo a una mayor institucionalización del proyecto, al tiempo que comienza a profesionalizarse, especialmente a través de la elección del jurado. Este queda integrado por una persona que ejerce el comisariado y otra que coordina la edición de los Encuentros, y se completa con figuras relevantes, desde la dirección de un museo y de una galería importantes, así como una más, experta en escultura, siempre procurando superar el marco geográfico malagueño y andaluz, para tener visiones desde otros territorios de España. Estas personas son, para el proyecto de este año, Carolina Parra, Paula Cabaleiro, José María Luna, Juan Francisco Rueda y Arturo Comas. Posee, este órgano, la capacidad de decisión sobre las propuestas que se presentan a los Encuentros, al tiempo que funciona como un catalizador desde el punto de vista artístico. Además, resulta definitorio a la hora de marcar las pautas a seguir, por lo que ostenta un peso específico en toda la estructura de «Genalguacil Pueblo Museo».

En esta línea de profesionalización, en estos momentos, el comisario de las exposiciones es Juan Francisco Rueda, quien asegura que: «La idea es, a través del arte, generar materiales de 


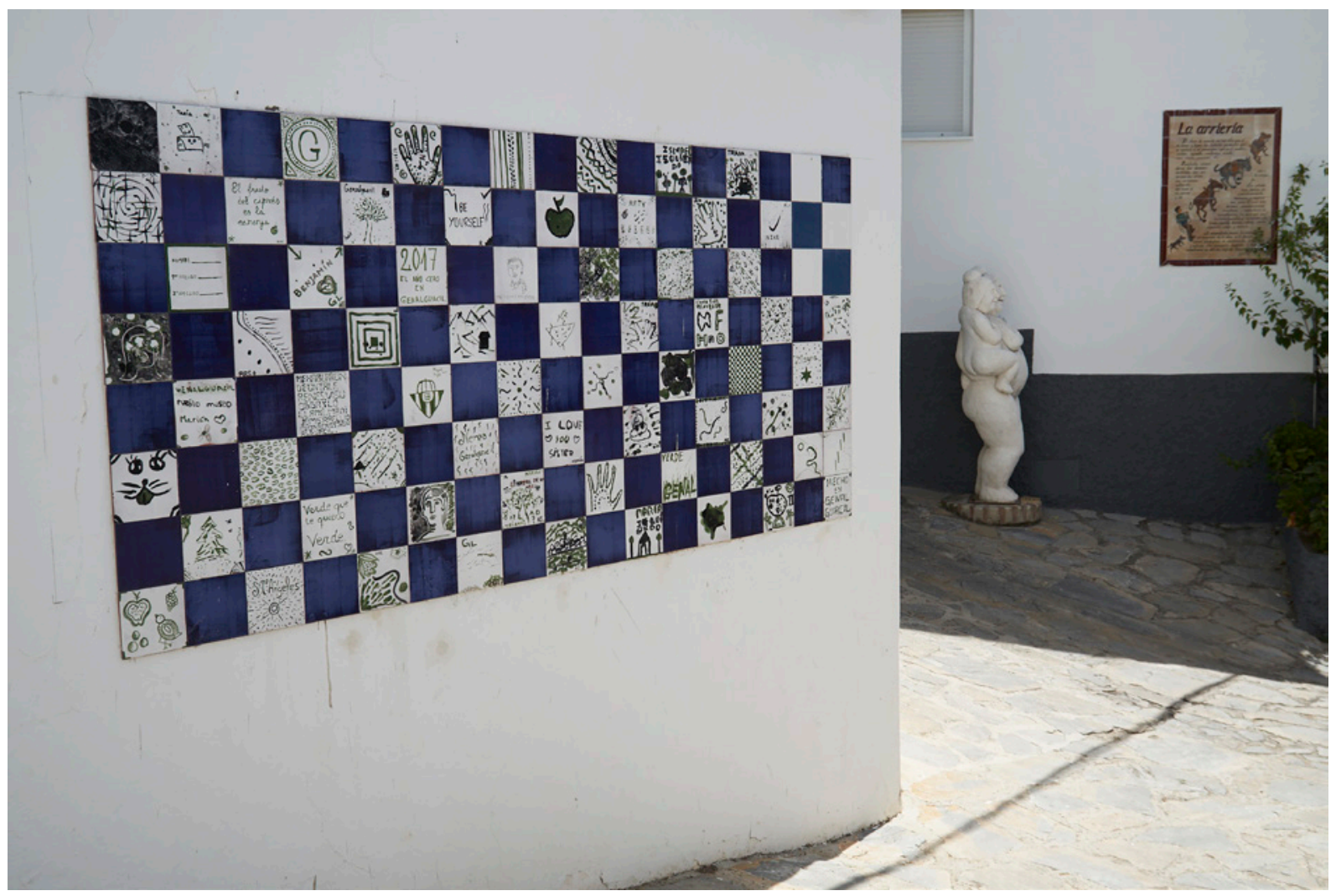

Mural realizado por los niños de Genalguacil durante los talleres de Arte Vivo 2017, dentro del proyecto «Pintar imaginarios». Al fondo, escultura $E l$ descansito de Aida Carvajal, Encuentros de Arte 2012, y mural cerámico explicando un antiguo oficio, el de los arrieros. Fotografía: Carmen Nájar.

reflexión, como demografía, geografía, topografía, ecología, historia...» (Rueda, 2017) y la coordinación de los Encuentros corre por cuenta de Arturo Comas. Obviamente, aparte de estas incorporaciones de índole más técnico, que aseguran un discurso y definen la línea artística, también se ha ido conformando una estructura organizativa y de gestión que resulta imprescindible para movilizar el volumen de objetivos y actividades que se ponen en juego.

Podemos asegurar que del entusiasmo que en sus inicios movió a sus organizadores, prácticamente hemos pasado a una auténtica pasión en la que el arte contemporáneo se yergue como la vela que mueve el barco. Muchos son los intereses que se persiguen, que Miguel Ángel Herrera sintetiza en la siguiente frase: "Cuando hablamos de Genalguacil y de sus Encuentros nos referimos a cultura, creación, modernidad, singularidad e inspiración» (Algarra y Centeno, 2014).

Con los años, la difusión de la experiencia y las relaciones que se han establecido con otras instituciones culturales y museísticas ha aumentado, interesándose por Genalguacil el periódico The New York Times, que le dedicó un artículo en septiembre de 2014 bajo el titular: To lure tourists a remote village in Spain, turns its eyes to the art, firmado por Raphael Minder. También se interesaron por el Proyecto museos como el Museo Nacional Centro de Arte Reina Sofía de Madrid, o el propio MoMA de Nueva York. Paralelamente, hoy existe un buen número de artistas verdaderamente atraídos por involucrarse y exponer sus obras, bien en las calles, bien en el Museo. Hay que reseñar que el devenir de muchos jóvenes creadores que llegaron a Genalguacil cuando iniciaban sus carreras, 
se ha visto notablemente unido al éxito en las mismas, como lo demuestra la presencia de casi todos ellos y ellas en las sucesivas ediciones de ARCO, en las que también participa el propio proyecto de «Genalguacil Pueblo Museo».

Por tanto, podemos decir que existe un sólido proyecto que, según sus organizadores, se sustenta en cuatro pilares que son: tradición, arte, cultura y naturaleza, y que se ha ido comprobando y mejorando con una ya importante experiencia acumulada y, como veremos más adelante, volcado hacia el futuro, como una apuesta muy seria en la que el arte contemporáneo es el fundamento para sacar al pueblo de la decadencia que asiste a los núcleos poblacionales del interior. En realidad, casi nos parece un derecho de sus moradores y, por tanto, este sería un claro ejemplo de ejercicio de justicia.

Cuatro programas, en resumen, sostienen, por el momento, el edificio del proyecto global «Genalguacil Pueblo Museo»: los Encuentros, las ediciones de Arte Vivo, el Museo y Lumen. $\mathrm{Si}$ el éxito puede medirse con números, solo decir que para este año de 2020 se han presentado 207 proyectos, provenientes de cerca de 20 países, y toda la dinámica que vive el pueblo ha entrado recientemente en el ranking del Observatorio de la Cultura de España.

Pero, como es de suponer, nada de este extraordinario montaje podría hacerse de espaldas a la población. La colaboración entre el vecindario es absoluta, de manera que se puede percibir el esmero con el que miman cada trozo de calle, cada esquina, cada muro... $y$ sus habitantes se convierten en cicerones espontáneos si la ocasión lo requiere. Todo el pueblo está surcado por una enorme diversidad de elementos que contribuye a que la estancia sea lo más agradable posible, en un afán por promover el turismo cultural como fuente de ingresos para la localidad. Por todo ello, los visitantes van y vuelven a Genalguacil. Repiten. Regresan con acompañantes a los que introducen -como si de iniciados se tratase-en una especie de culto, casi un peregrinaje. Los llevan a perderse entre el laberinto mágico de sus calles y sus obras de arte en un estimulante deambular estético. Al final, siempre desean quedarse.

\section{La colección}

Las obras deben cumplir con unos requisitos: la adecuación al lugar donde quedará ubicada, la revalorización del acervo natural y etnográfico como valores populares innegables de la localidad y, por otro lado, que forme parte de un argumento global, que no sea un verso suelto sin conexión con todo el discurso expositivo del museo, constituido por las calles y los espacios públicos de Genalguacil. Los creadores y creadoras se han ido convirtiendo con las sucesivas ediciones en verdaderos narradores de historias y emociones artísticas, y sus argumentos y consideraciones circulan de la mano, entre el conocimiento y la experiencia, entre la emoción y el rescate de la tradición, entre la técnica y la cultura.

No se trata, por tanto, de promover la creación de un muestrario ornamental que se limita a decorar determinados rincones sin que exista un hilo conductor, un motivo o una intención reflexiva. Tampoco es lo que se conoce como los sculpture parks, con obras de artistas, más o menos consagrados, y que forman una especie de colección, algo similar a lo que podemos encontrar en el -por otro lado impresionante- recinto de Montenmedio en Vejer (Cádiz), en el que se cuenta con intervenciones de James Turrel o de Marina Abramovic, y en el que existe una íntima relación entre el arte y la naturaleza con su sucesión de proyectos site-specific. En esa misma línea podemos encuadrar otras experiencias como el Chillida Leku, en Guipúzcoa, o el Museo de las Esculturas de Leganés, en Madrid. Ejemplos, por otro lado, también próximos al land art, expresión que 


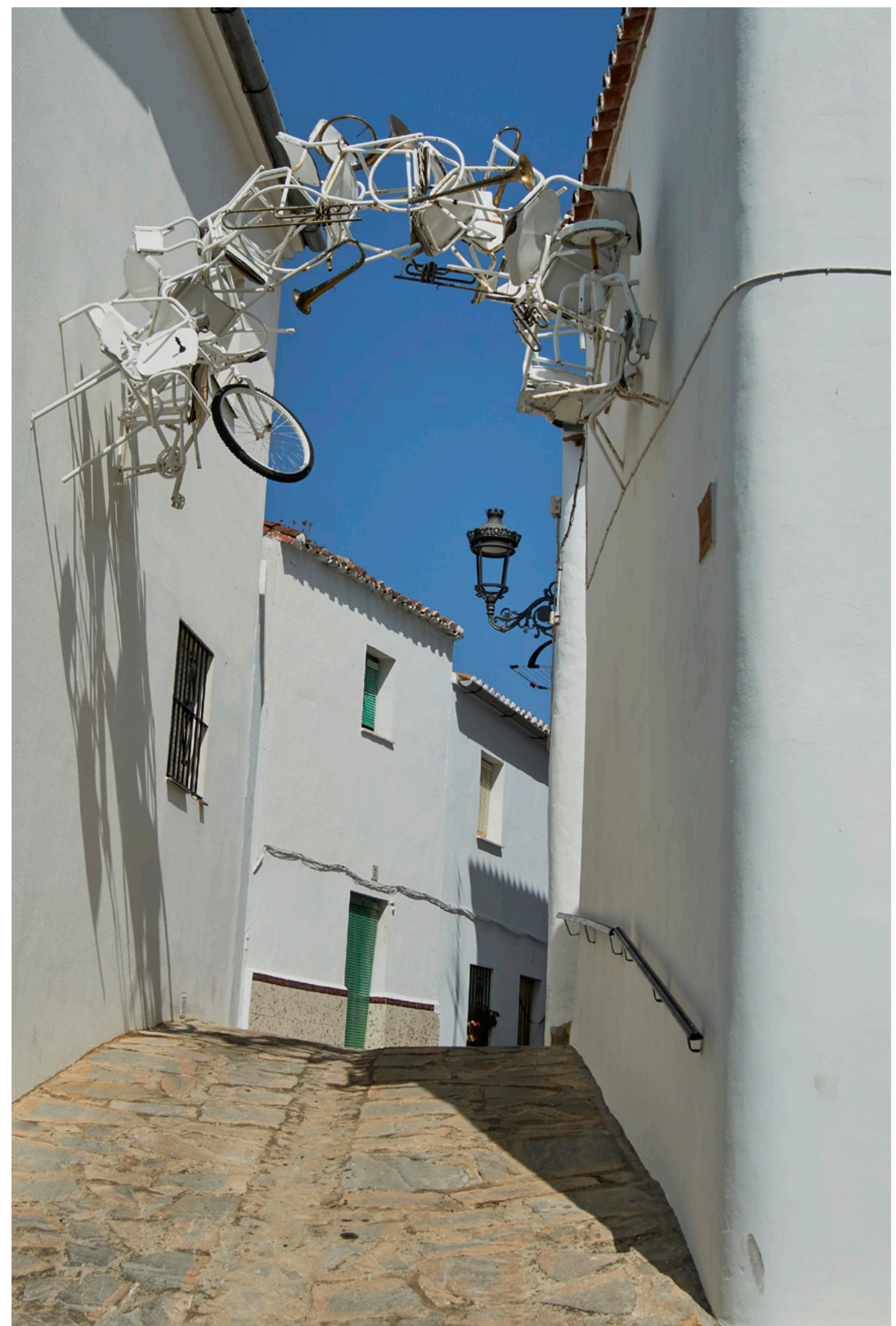

Arco del viento, de Isidro López-Aparicio. Encuentros de Arte 2016. Fotografía: Carmen Nájar. 


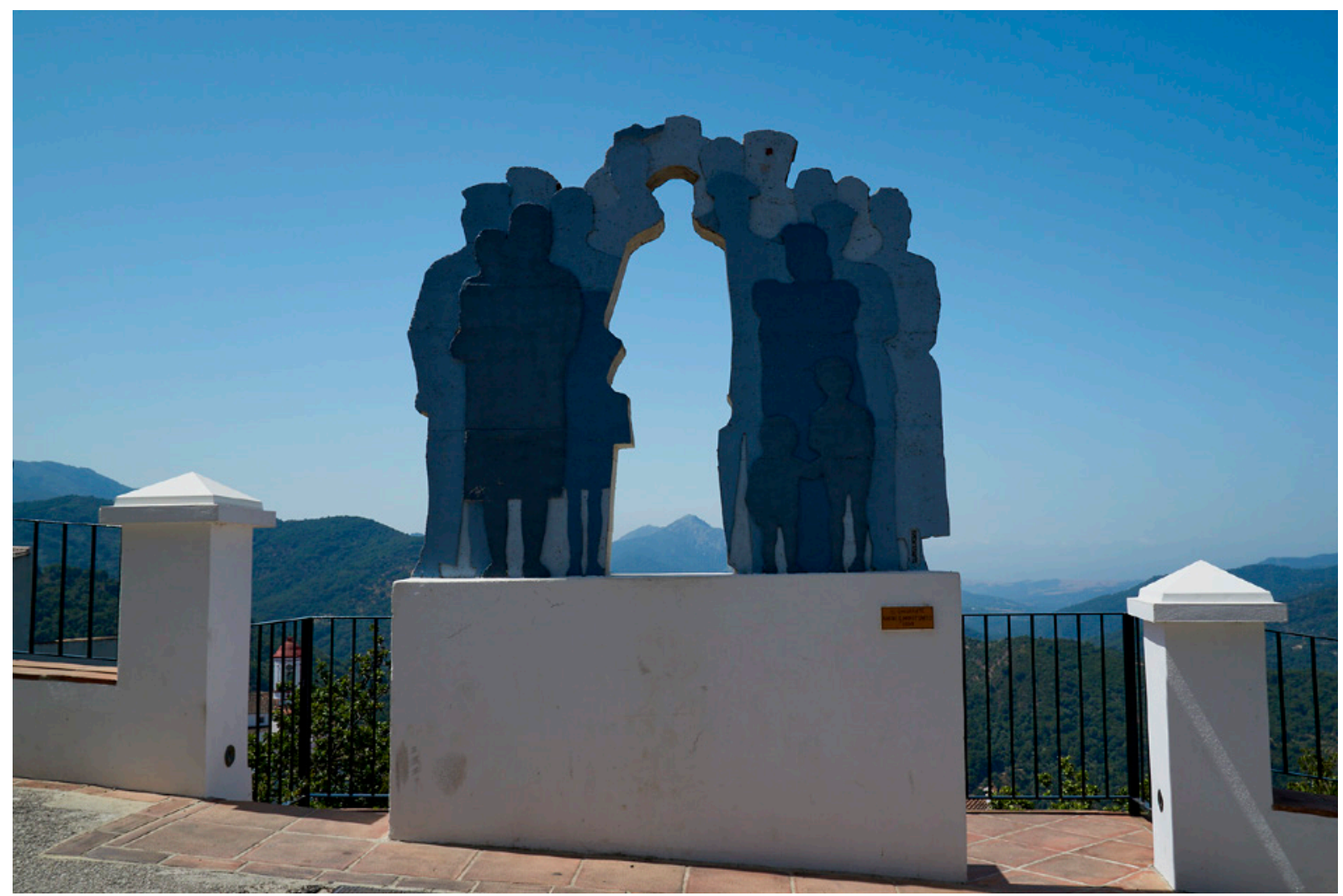

El emigrante, de Andrés Montesanto, Encuentros de Arte 2008. Fotografía: Carmen Nájar.

designa a aquellas actuaciones realizadas en la naturaleza virgen, nociones que están próximas a una concepción que, en realidad, se aleja un tanto de la idea de museo para adentrarse en el concepto de paisaje contemporáneo, como el que existe en el río Lérez, en Pontevedra, la Illa do Cobo. Y tampoco estamos ante un caso de museo mayoritariamente grafitero, en el que los murales se convierten en el tema preponderante, como es el caso de Fanzara, en Castellón, otro pueblo que se sustenta en el arte para resolver situaciones complicadas. Como también han hecho en Romangordo (Cáceres), donde una serie de pinturas en las paredes de las casas, recrean escenas costumbristas del pasado del lugar y sus habitantes, formando extraordinarios trampantojos.

Porque entre esta desbordante panoplia de estímulos y productos artísticos que podemos encontrar en Genalguacil, quizá lo principal sean los valores sociales que la población ha ido atesorando. Ya que, a pesar de las fechas fijas en el calendario, no se trata de un hecho puntual en el tiempo, es un continuo habitar de sus gentes en lo que podemos denominar una comunidad cultural, la musealización de un ecosistema humano. De ahí que se le catalogue como el único museo habitado del mundo.

Genalguacil es, como puede verse, algo diferente y especial. Es el pueblo performance, ya quela interacción entre puebloy artista, entre visitante y pueblo es constante. Genalguacil está vivo y tal y como pasa en las performances, quienes asistimos a ellas formamos parte de la magia y del momento único e irrepetible de la creación. Para los genalguacileños y para los artistas es muy importante la colaboración mutua que nos hace a todos cómplices de este arte contemporáneo, que se crea expresamente para los rincones de sus calles y que inhala $y$ 


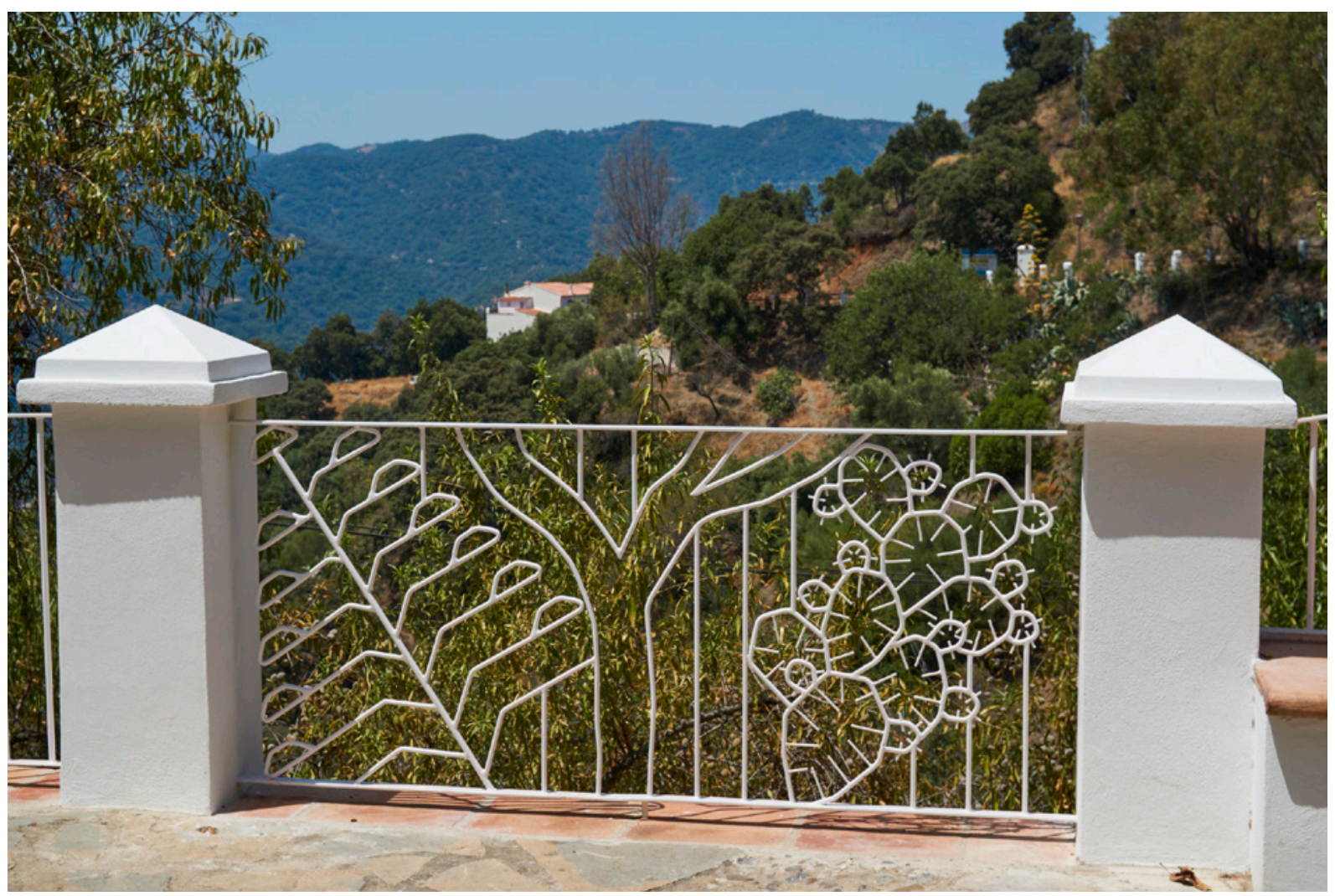

Barandilla de Tamara Arroyo. Intervención expandida del proyecto «Forjando identidades. Construyendo escenarios». Arte Vivo 2017. Fotografía: Carmen Nájar.

exhala el mismo aire que todos los que allí están. A través de esa interacción permanente, los habitantes forman parte del museo, son piezas vivientes de la colección.

Es tal la simbiosis que sucede que las obras -conformando lo que podemos llamar una exposición expandida- participan de la mutabilidad y se modifican con el paso de las horas, la luz, los meteoros, las estaciones... $\mathrm{O}$ terminan allí su efímera vida de manera apoteósica, igual que una vez se les dio aliento.

Resulta difícil plasmar en palabras lo que allí sucede, no solo durante los eventos, exposiciones, cursos, sino durante todo el año. Hay, por ejemplo, un rinconcito con dos bancos y una escultura cerámica con azulejos con un gato acostado en su cénit, obra de Ana Victoria Navarro, titulada Contador de historias, que además de ser obra plástica, invita a sentarse a leer, o quizás a escribir, y continuar haciendo arte. Otra obra, una figura cerámica de una señora mayor con un moño alto y posición firme y brazos en jarra, aunque ligeramente taciturna, nos dice «estoy hasta el moño de subir cuestas» que así titula la obra su autor Juan Ramón Gimeno.

Algunas obras, además de su función puramente estética, tienen otra de mobiliario urbano, como es el caso de Acémilas, del mismo autor anterior, donde a tres cabezas de burro les sale agua de sus bocas, porque es una fuente. O la aportación de Ralf Kiwus, titulada Obra teatral de azulejos y madera, donde un hombre-banco parece ver la tele, que no es más que un marco vacío donde poder admirar las preciosas vistas del entorno. Otras son una evidencia del compromiso de sus autores, como El emigrante, fruto de los Encuentros de 2008 del artista Andrés Montesanto, quien migró de Argentina a 


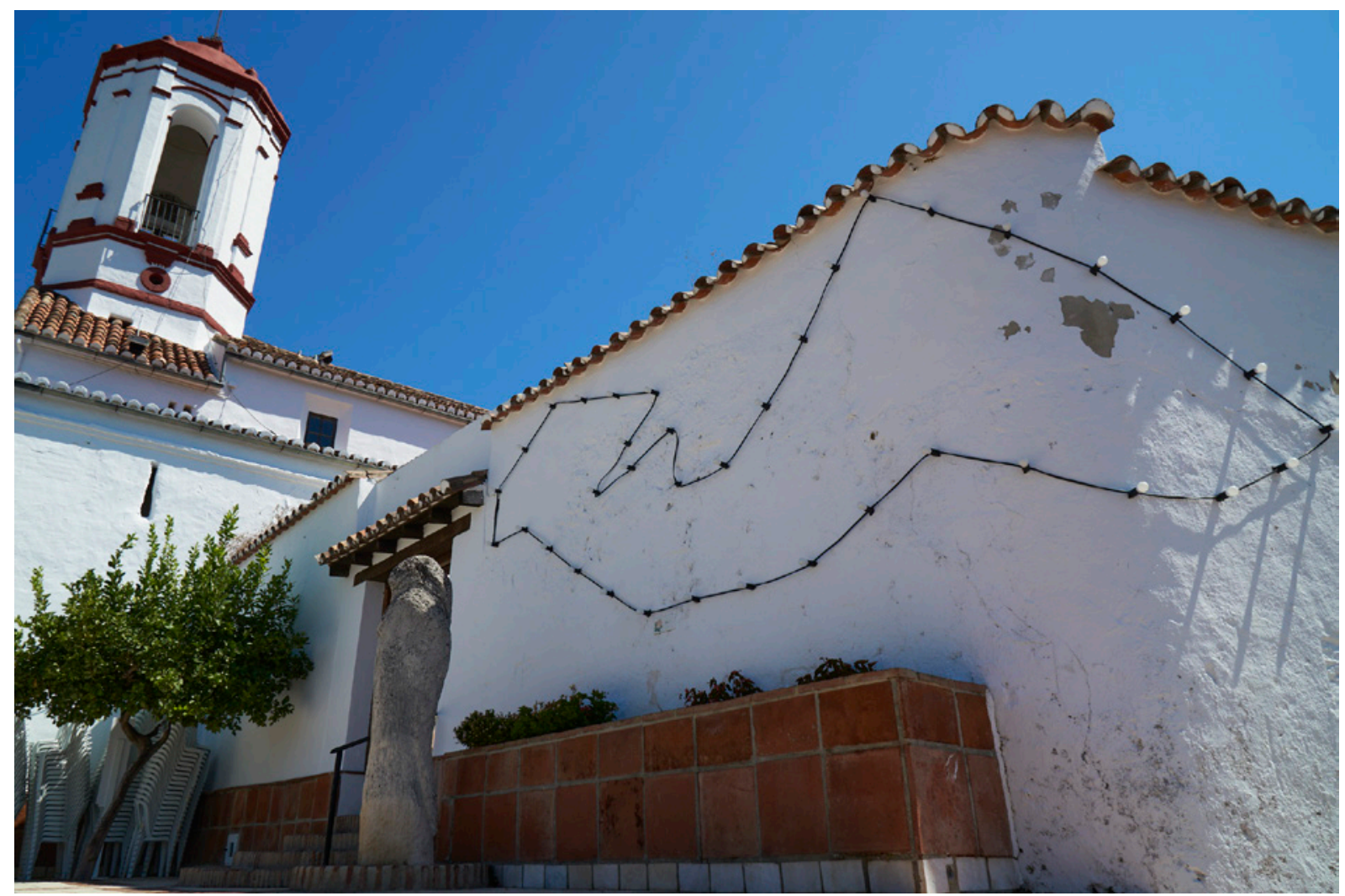

Festival Lumen 2019. Obra: Del caño al coro, de Sonia Navarro. La luz artificial de las bombillas refleja el recorrido que hacían las mujeres cada día: casa-iglesia-lavaderos-casa.

Málaga y que, por tanto, conoce de qué habla y utiliza su arte para denunciar injusticias y posicionarse en temas reivindicativos. Esta obra tiene su complementaria, El inmigrante, en Derio (Vizcaya), adonde, la fuerte deriva poblacional, llevó a muchos genalguacileños.

Junto a ellas, algunas muestras, como «Territorios. A las Ciencias Sociales por el Arte», de los artistas José Medina Galeote y Françoise Vanneraud. La del primero consistió en una intervención en las persianas -por tanto, elementos cambiantes con su uso cotidiano- de puertas y ventanas pintadas de celeste con motivos blancos y verdes, fruto de un diálogo entre los autores que: «nos permite analizar distintos aspectos de un grupo social o un enclave» (Rueda, 2018). O el Arco de Viento, que facilita a su autor, Isidro López Aparicio, reflexionar "sobre la futilidad de lo que nos rodea» (López Aparicio, 2016).
Fernando Renes y Arancha Goyeneche, empleando una amplia gama de recursos, como la cerámica, la azulejería, lo popular, la tradición, lo vernáculo y la propia Historia del Arte (Rueda, 2017), nos dejaron sus obras, que se encuadraron dentro del proyecto «Pintar imaginarios». De la edición de Arte Vivo de 2019, en algunos miradores del pueblo han quedado unas barandillas de forja que reproducen motivos de plantas autóctonas, que se deben a la artista Tamara Arroyo.

En otro orden de cosas, la Galería T20, que ha iniciado un proceso de deslocalización de sus actividades, habiendo celebrado sendas exposiciones en Londres en los años 2018 y 2019, se ha trasladado en 2020 a Genalguacil, en palabras de sus promotores: "porque hay una razón aún más importante para instalarnos allí este verano, y es que lo que ocurre en esa belleza histórica de la Serranía de Ronda es 
lo más interesante del panorama artístico español» (T20, 2020). Pues bien, dentro de la oferta de la galería, el artista Miguel Fructuoso, en calidad de artista invitado a los Encuentros, plantea una revisión de algunos de los hitos de la Historia del Arte en su obra Pastoral.

Y así hasta unos 200 autores y obras en las quela multitud de materiales, soportes, técnicas y lenguajes expresivos nos ponen en contacto con una colección de arte contemporáneo en la que el eclecticismo es la marca, eso sí, sin estar reñido con la congruencia narrativa. Podríamos analizarlas todas, una a una, pero mejor, vayan a Genalguacil ustedes mismos $\mathrm{y}$ formen parte del prodigio de andar por él. Sumérjanse en un juego para los sentidos y las emociones. Circulen por los rincones específicos para cada pieza en los que se conjugan los elementos tradicionales del urbanismo propio con las instalaciones y obras contemporáneas, en medio de un entorno en el que la naturaleza juega a ser un espectacular telón de fondo. Dediquen tiempo al abandono de la placidez de lo probable, para acercarse a la inquietud de lo sorprendente.

\section{El futuro}

Desde la solidez y la veteranía que orienta la gestión, se plantea abrir el abanico de actuaciones y existen algunas líneas, en parte ya comentadas más arriba, que apuntan hacia la consolidación del formato.

La generación de exposiciones temporales, para ofrecer propuestas artísticas de forma continuada, con la celebración de unas seis al año, o afianzar el proyecto «Lumen», son objetivos a muy corto plazo, puesto que ya están en marcha.

Pero, quizá la apuesta más decidida sea la consolidación de la Fundación, de forma que se puedan superar obstáculos con otras administraciones o entidades y, sobre todo, que se garantice una cierta emancipación de las iniciativas meramente municipales. De esta forma, se institucionaliza el proyecto "Genalguacil Pueblo Museo» y se liberaliza de posibles luchas

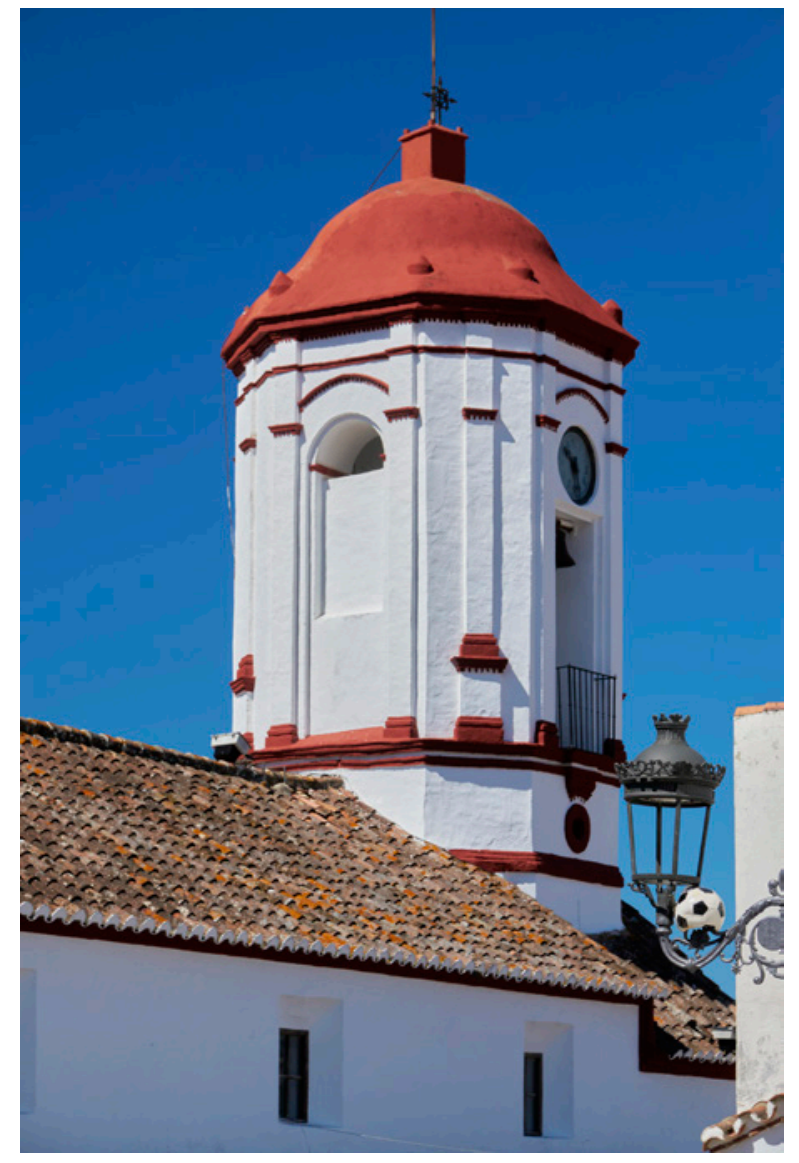

Proyecto: «10 balones embarcados», de Miguel Ángel Moreno. Encuentros de Arte 2016. Fotografía: Carmen Nájar.

partidistas en el seno del Ayuntamiento, del mayor o menor acierto de los políticos y gestores de turno y de posibles vaivenes económicos o de otra índole que puedan acontecer en el futuro. Es una manera de asegurar el porvenir del proyecto, con independencia de las personas que estén al frente $y$, especialmente, entregarle una determinada autonomía en el diseño, la gestión y el desarrollo de los planes. Esta idea incide también en el deseo de profesionalización que hemos apuntado anteriormente, y que lleva a los actuales agentes a ampliar la presencia de técnicos y especialistas en arte contemporáneo, si bien continúe siendo una iniciativa indudablemente pública y de compromiso con el pueblo y sus habitantes. La Fundación actuará como agente dinamizador para que «Genalguacil Pueblo Museo» tenga un impacto social y económico. 


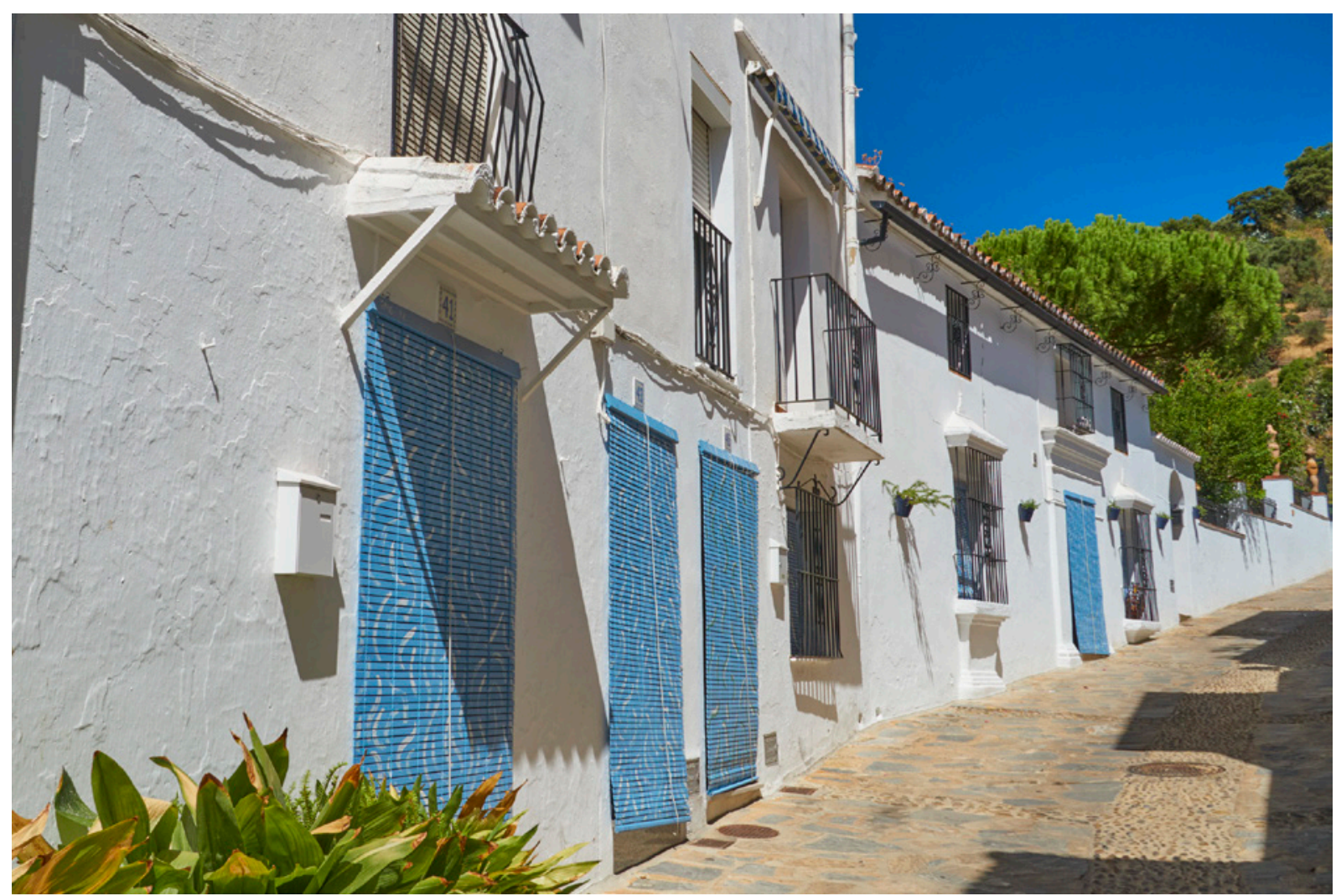

Intervención 55 persianas, de José Medina Galeote dentro del proyecto «Territorios. A las Ciencias Sociales por el Arte». Artista invitado en los Encuentros de Arte 2018. Fotografía: Carmen Nájar.

La articulación de donaciones, mecenazgos, depósitos, etc. también tiene cabida en este nuevo organigrama, y la figura de un $\mathrm{Pa}$ tronato, igualmente, se incluiría dentro del esquema de funcionamiento, como un soporte económico y patrimonial muy interesante para sostener todo el proyecto y como vehículo de configuración de relaciones y acuerdos en el que las iniciativas privadas encuentren un marco en el que integrarse. Se contemplan cuatro niveles de implicación económica para otras tantas figuras denominadas: familias, colaboradores, defensores y protectores del Proyecto. Cada uno tendrá acceso a unos beneficios concretos, a una predeterminada presencia y a un peso específico a la hora de adoptar acuerdos.

Si bien aún está por definirse de forma definitiva, la idea que subyace es que exista un tercio de presencia pública -Ayuntamiento,
Diputación, etc.-, otro tanto privada y el otro tercio destinado a profesionales, a la hora de la toma de decisiones en el seno de la Fundación, a través del Patronato. Quienes apoyen, patrocinando los proyectos, estarán presentes en las asambleas y en los acuerdos y fallos que se adopten, acorde con la cantidad puesta a disposición del sostenimiento de los mismos.

Siguiendo en esta dirección, en la que los recursos privados podrán tener protagonismo en el proyecto, ya se habla de disponer de una posible Residencia para Artistas, como respuesta privada a la necesidad de acondicionar alojamientos para aquellos creadores y creadoras que intervengan en las planificaciones o en la multitud de actividades programadas, así como para quienes, motu proprio, expresen el deseo de trabajar en Genalguacil por una temporada, como lugar de indudable inspiración y estímulo. La realidad es que ya existen varias 


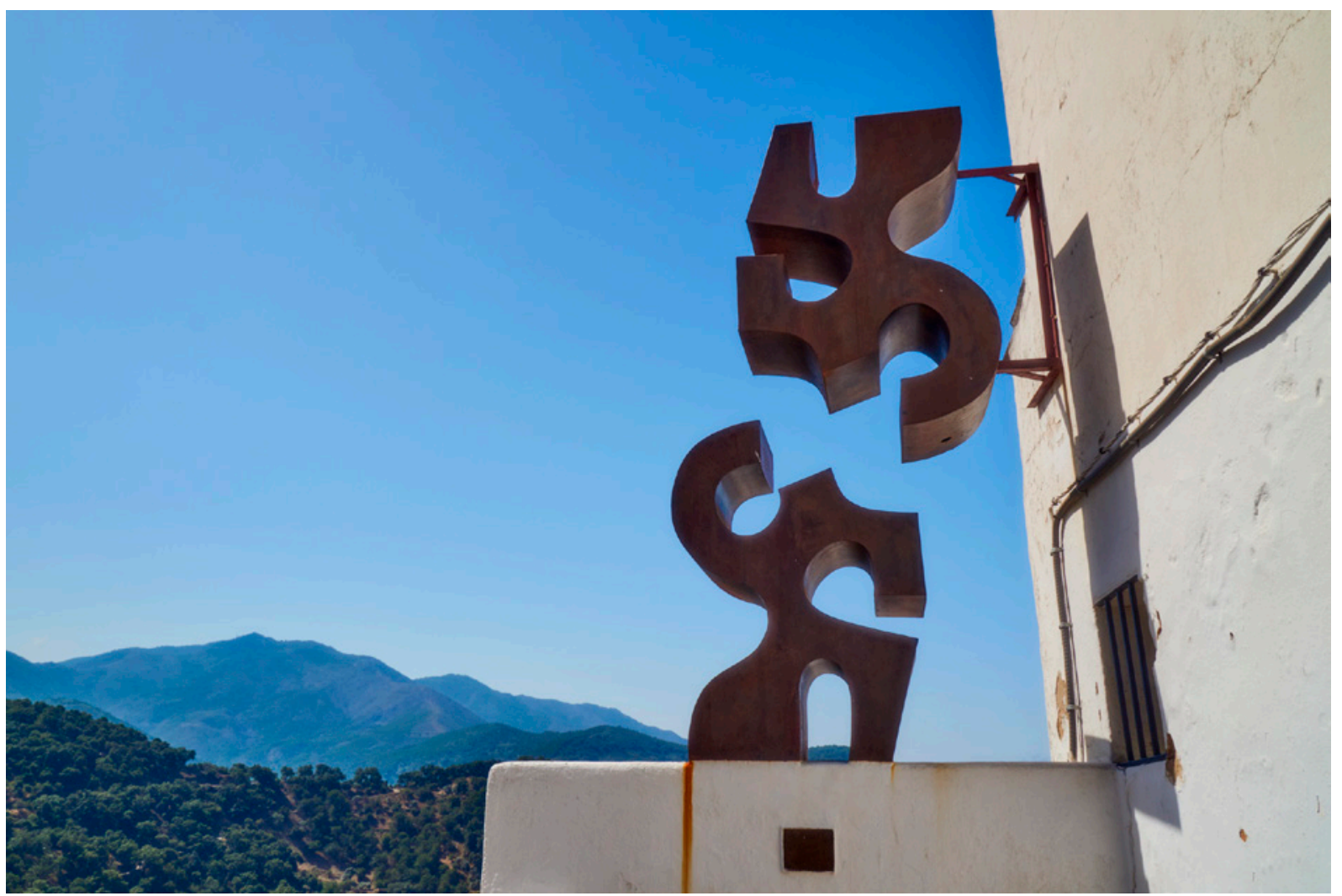

Abrazando el aire, de Antonio M. y Nuria Haro. Encuentros de Arte 2004. Fotografía: Carmen Nájar.

personas del mundo de la creación que se han instalado en Genalguacil por su atractivo, y cuenta con incondicionales, como la relevante figura de Benjamín Ramírez.

De igual modo, tampoco se olvida la faceta formativa, especialmente dirigida hacia la población más joven del municipio. Técnicos de museo o guías turísticos son dos especialidades que se van a hacer precisas para las labores propias museísticas o las de dinamización y explicitación de todos los elementos artísticos y ambientales disponibles. No podemos olvidar que, detrás de cada una de las obras expuestas en Genalguacil, existe una historia interesante e importante, y darlas a conocer, así como el análisis de las mismas desde un punto de vista formal, contribuirían, de forma notable, a mejorar el diálogo entre las propias obras y quienes las contemplan y las disfrutan.
Otra de las funciones de esta Fundación sería la editora, ya que se contempla la existencia de una editorial propia, como vehículo de difusión de las obras, los artistas y las actividades, y cuidar, así, esta parcela de conocimiento y de divulgación.

No obstante todas estas novedades, viren por donde viren los vientos del futuro, lo que es incuestionable, es que el proyecto «Genalguacil Pueblo Museo» pertenece a sus gentes y es objeto de orgullo y le otorga identidad a la comunidad. Y es que estamos, por tanto, ante una unión entre la obra y sus usuarios -casi una confabulación- ya que estos se convierten en los primeros en disfrutarla, pero también en protectores y cuidadores de ella, integrándola en sus quehaceres diarios y en su hábitat ordinario, por lo que pasa a formar parte de su paisaje físico, pero, lo que es más importante, también de su paisaje emocional. 


\section{REFERENCIAS Y BIBLIOGRAFÍA}

Algarra Navas, Daniel y María Centeno Sánchez (2014) 20 aniversario Genalguacil. Encuentros de Arte, Plan de dinamización del producto turístico Serranía de Ronda.

CAC MÁlaga. Disponible en http://cacmalaga.eu [Fecha de consulta 12/08/2020]

CArrero, Marisa (2014) «James Turrell: biografía, obras y exposiciones», en Alejandra de Argos. Disponible en https://www.alejandradeargos.com/ index.php/es/completas/32-artistas/365-jamesturrell-biografia-obras-y-exposiciones [Fecha de consulta 5/09/2020]

«José Medina Galeote: "Soy un artista muy austero en medios y procesos"», en El Cultural. Disponible en https://www.elcultural.com/Jose-Medina-Galeote [Fecha de consulta 21/08/2020]

"Qué es un Museo Abierto ", en EVE Museos e Innovación. Disponible en https://www. evemuseografia.com/2020/03/24/que-es-unmuseo-abierto/ [Fecha de consulta 22/08/2020]

Página de Facebook de Miguel Ángel Herrera Gutiérrez. Disponible en Facebook.com/100004389512675/ posts/1721790364643931/?app=fbl [Fecha de consulta 21/08/2020]

«José Medina Galeote», en Fucares. Disponible en https://www.fucares.com/artista/jose-769-medinagaleote/ [Fecha de consulta 10/08/2020]

Fundación NMAC. Disponible en https://fundacionnmac. org/es/ [Fecha de consulta 2/08/2020]

«Genalguacil y sus encuentros de arte (2018)», en Genalguacil. Disponible en http://www.genalguacil. es/12101/genalguacil-y-sus-encuentros-dearte-2018 [Fecha de consulta 1/08/2020]

Gómez López, María (2019) «El Festival de las Artes de Asilah: la ciudad como escenario y el redescubrimiento de la cotidianidad», en Afribuku. Disponible en http:// www.afribuku.com/el-festivalde-las-artes-de-asilah-la-ciudad-como-escenario-yel-redescubrimiento-de-la-cotidianidad/ [Fecha de consulta 4/09/2020]

Gonzalo Polo. Disponible en http://gonzalopolo.es/ [Fecha de consulta 4/08/2020]

Juan Ramón Gimeno. Disponible en http:// juanramongimeno.com/ [Fecha de consulta 5/08/2020]

Jong, Adriaan de y Mette SkougaArd (1992) «Los primeros museos al aire libre. La tradición de los museos de tradiciones», Museum. Museos etnográficos y los museos al aire libre, 175, XLIV, 3, 1992: 151-157. Disponible en https://unesdoc. unesco.org/ark:/48223/pf0000092980_spa
LÓPEZ APARICIO, Isidro (2016) «Memorias del Valle del Genal. Arco de viento», en Vimeo. Disponible en https:/vimeo.com/226029612 [Fecha de consulta 15/08/2020]

Marta de Pablo. Disponible en http://martadepablod. org/ [Fecha de consulta 20/08/2020]

MARTÍnez Sierra, Jovino (2013) «Luz, materia y espacio», Papeles de cultura contemporánea, Periferias escultóricas, 18: 48-56.

Minder, Raphael (2014) «To Lure Tourists, a Remote Village in Spain Turns Its Eye to the Arts ", en The New York Times. Disponible en https://www. nytimes.com/2014/09/04/world/europe/to-luretourists-a-remote-village-in-spain-turns-its-eye-tothe-arts.html [Fecha de consulta 5/09/2020]

Nuevo, Mar (2020) «El primer museo habitado. Así salvó el arte a Genalguacil», en Tendencias hoy. Disponible en https://www.tendenciashoy.com/ arte/plastica/de-exposicion-a-museo-habitado-asisalvo-el-arte-a-genalguacil.html [Fecha de consulta $1 / 09 / 2020]$

Pedro Lorente, Jesús (2013) «¿Qué es un museo de escultura al aire libre?», Papeles de cultura contemporánea, Periferias escultóricas, 18: 71-84.

PÉrez CASTILlo, María Regina (2019) «Lumen: un festival dedicado a la luz en Genalguacil». Disponible en https://www.plataformadeartecontemporaneo.com/ pac/ lumen-festival-dedicado-la-luz-genalguacil/ [Fecha de consulta 3/09/2020]

Renes, Fernando (2018) Fernando Renes Genalguacil, Editorial Popurit.

RuedA, Juan Francisco (2017) «Pintar imaginarios. Fernando Renes y Arancha Goyeneche en Genalguacil». Disponible en https:// juanfranciscorueda.wordpress.com/2017/11/15/ pintar-imaginarios-fernando-renes-y-aranchagoyeneche-en-enalguacil/ [Fecha de consulta 5/09/2020]

- (2019) «Françoise Vanneraud/José Medina Galeote, Territorios. A las ciencias sociales por el arte». Disponible en https://juanfranciscorueda. wordpress.com/2018/10/29/territorios-a-lasciencias-sociales-por-el-arte-vanneraud-medinagaleote-en-genalguacil-pueblo-museo/ [Fecha de consulta 25/08/2020]

ZEUnER, Christopher (1992) «Los museos al aire libre: celebración y perspectivas», Museum, 175, xLIV, 3: 147-148. Disponible en https://unesdoc.unesco.org/ ark:/48223/pf0000092980_spa

VARINe, Hugues de (2020) «Todo lo que querías saber de los museos al aire libre». Disponible en https:// evemuseografia.com/2020/03/24/que-es-unmuseo-abierto/ [Fecha de consulta 23/08/2020] 


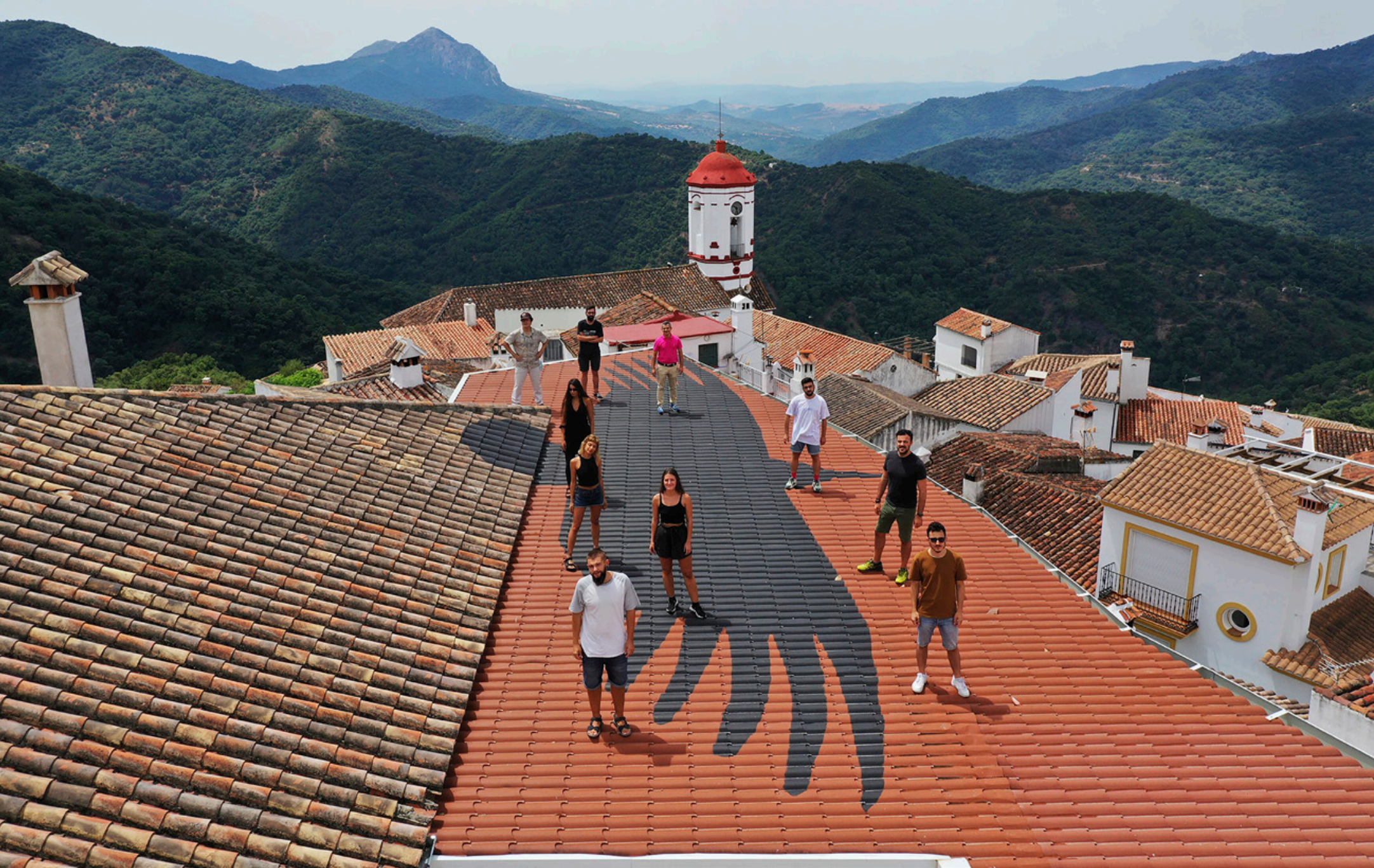

Posado de los artistas residentes en los Encuentros de Arte 2020, el alcalde y el coordinador de los mismos sobre la obra La sombra del buitre de Juan Zamora, Encuentros 2014. Fotografía: Jesús Ponce.

Recibido el 9 del 9 de 2020

Aceptado el 8 del 10 de 2020

BIBLID [2530-1330 (2020): 110-127] 